\title{
Exitoso cultivo in vitro de gametocitos de Plasmodium falciparum
}

\author{
Ana Mercedes Rada, Carolina Moreno, Silvia Blair
}

Grupo Malaria, Universidad de Antioquia, Medellín, Colombia.

Institución en donde se llevó a cabo el trabajo:

Sede de investigación Universitaria, SIU, Universidad de Antioquia.

Introducción. Los estadios sexuales de Plasmodium falciparum han sido menos estudiados que los estadios asexuales. Al parecer, esto se debe a la carencia de cultivos estandarizados in vitro y a la dificultad de reconocer sus estadios de desarrollo. Estos hechos no permiten el estudio de aspectos biológicos, aspectos metabólicos, expresión de genes y síntesis de proteínas durante los estadios sexuales, temas de interés en la investigación de nuevos medicamentos antipalúdicos, principalmente los aislados de plantas, y la identificación de un potencial blanco contra Plasmodium.

Objetivos. Establecer un cultivo in vitro de gametocitos, con la identificación de sus cinco estadios de desarrollo, y asegurar su continua producción.

Materiales y métodos. El cultivo in vitro de gametocitos se realizó a partir de la cepa NF54 de $P$. falciparum en medio RPMI, con determinación de la parasitemia asexual y sexual, adición de glóbulos rojos A-Rh+ sólo el primer día de cultivo y cambio diario del medio con adición de mezcla de gases $\left(90 \% \mathrm{~N}_{2}, 5 \% \mathrm{O}_{2} ; 5 \% \mathrm{CO}_{2}\right)$, asegurándose que el cultivo se mantuviera a $37^{\circ} \mathrm{C}$. Cuando la parasitemia asexual estuvo entre $3 \%$ y $5 \%$, se comenzó a agregar el doble de volumen de medio.

Resultados. Se obtuvieron gametocitos en estadios I, II y III a partir del día 11 de cultivo y estadios IV y $\mathrm{V}$ a partir del día 14 de cultivo.

Conclusiones. Se estandarizó un cultivo in vitro para estadios sexuales de $P$. falciparum que puede usarse para futuros estudios de evaluación de compuestos, naturales o sintéticos, que actúen sobre los gametocitos, lo cual podría permitir el desarrollo de nuevas estrategias de control contra el paludismo.

Palabras clave: Plasmodium falciparum, in vitro, paludismo, Anopheles.

\section{Successful in vitro culture of Plasmodium falciparum gametocytes}

Introduction. The sexual stages of Plasmodium falciparum have not been studied in as much detail as the asexual stages due to the lack of standardized in vitro cultures as well as difficulties in identifying the sexual development stages of the parasite. These difficulties hamper the studies on biology, metabolism, gene expression and protein synthesis during sexual stages. Each of these facets are important targets in antimalarial drug research, particularly the identification of potential therapeutic agents against Plasmodium (derived mainly from plants). Objectives. An in vitro culture of $P$. falciparum gametocytes was established to standardize the identification of its five developmental stages and ensure their continuous production.

Materials and methods. The in vitro gametocyte culture was established from the $P$. falciparum NF54 strain in RPMI culture medium, with assessment of the asexual and sexual parasitaemia. The medium was supplemented with type $\mathrm{A} R \mathrm{~h}+$ red blood cells only on the first day of culture. Subsequently, the medium was changed daily, together with addition of gas mixture $\left(90 \% \mathrm{~N}_{2}\right.$, $5 \% \mathrm{O}_{2}, 5 \% \mathrm{CO}_{2}$ ) and maintenance of the culture temperature at $37^{\circ} \mathrm{C}$. When asexual parasitaemia reached 3 to $5 \%$, the medium was changed by doubling its volume.

Conclusions. We standardized an in vitro culture for sexual stages of $P$. falciparum that can be used for future studies about evaluation of compounds of synthetic or natural origen against the sexual stage, which may permit to develop new control strategies against malaria.

Key words: Plasmodium falciparum, in vitro, malaria, Anopheles. 
Los estadios sexuales de Plasmodium falciparum llamados gametocitos son los responsables de la infección del mosquito vector Anopheles y los estadios asexuales son los responsables de la sintomatología en el hombre (1). Se conoce que, mediante un proceso complejo de desarrollo del parásito, sólo una pequeña fracción de los parásitos asexuales evoluciona al estadio sexual (2), y se ha observado que las densidades de gametocitos en sangre periférica son considerablemente más bajas que las de los parásitos asexuales (3). Algunos reportes señalan que la proporción entre gametocitos y estadios asexuales de $P$. falciparum es de 1:10 (4-7) y otros señalan que es de 1:156 (3).

El gametocito, célula especializada, acomoda su vida a diferentes ambientes y pasa por varios estadios en los que se pueden observar no sólo diferencias morfológicas sino también metabólicas; también, cambios en la expresión de ciertos genes y síntesis de diversas proteínas que reflejan una preparación de los gametocitos para los drásticos cambios futuros (8).

Uno de los aspectos más importantes y desconocidos de este estadio sexual es que durante el proceso de maduración atraviesa por cinco estadios morfológicamente diferentes, clasificados como estadios I al V, los cuales expresan proteínas sobre la superficie de los eritrocitos infectados (9). Inicialmente, Field y Shute, en 1956 (10), describieron los cinco estadios de maduración de los gametocitos de $P$. falciparum. Posteriormente, estos fueron caracterizados por microscopía electrónica, en publicaciones de Cheryl Lobo y Nirbhay Kumar, en 2000 (11), yArthur Talman y colaboradores, en 2004 (8), quienes describieron las características morfológicas de los gametocitos en sus estadios inmaduros I, II, III y IV, y del gametocito maduro en estadio $\mathrm{V}$.

Por el interés que tiene esta fase sexual de Plasmodium, desde hace varios años se han

\footnotetext{
Correspondencia:

Silvia Blair, Grupo Malaria, Universidad de Antioquia, Calle 62 № 52-59, torre 1, Sede de Investigación Universitaria. SIU, Medellín, Colombia.

Teléfono: (574) 210 6486; fax: (574) 2106487

sblair@quimbaya.udea.edu.co

Recibido: 25/04/08; aceptado:14/08/08
}

desarrollado técnicas de cultivo para obtener gametocitos en sus diferentes estadios y poder estudiarlos in vitro. La primera descripción de cultivo in vitro de gametocitos de $P$. falciparum se realizó en 1929 por Row, quien presentó evidencia del crecimiento in vitro de gametocitos de estadios inmaduros (I, II, III y IV), pero no hubo formación de gametocitos maduros (V) (12). A partir de ese momento, se desarrollaron otras técnicas de cultivo in vitro para la obtención de gametocitos.

En 1976, Trager y Jensen (13) reportaron el mantenimiento de un cultivo continuo de $P$. falciparum en eritrocitos humanos; los parásitos fueron obtenidos de monos Aotus trivirgatus infectados; realizaron diluciones de los parásitos por la adición de eritrocitos humanos con intervalos de tres a cuatro días y cambio diario de medio de cultivo, y obtuvieron así gametocitos imperfectos después de dos meses de mantenimiento. También en 1976, Smalley (14) realizó la técnica de microcultivo que permitió el desarrollo in vitro de gametocitos de $P$. falciparum morfológicamente maduros.

Posteriormente, aparecieron los cultivos manuales, que con la adición de hipoxantina lograron la producción de gametocitos maduros de $P$. falciparum (15-17), y los cultivos automatizados, que buscaban el desarrollo y la maduración de gametocitos usando tratamientos con la $\mathrm{N}$-acetil glucosamina para sincronización del cultivo, y se logró la producción en poco tiempo de los cinco estadios sexuales de $P$. falciparum diferenciables morfológicamente $(18,19)$.

Estas técnicas de cultivo buscaban de una manera simple obtener gametocitos en cantidad suficiente, diferenciables morfológicamente e infectantes, para lograr estudios futuros relacionados con el desarrollo de una vacuna que bloquee la transmisión.

En Colombia, no se ha reportado hasta ahora ningún estudio que utilice el cultivo in vitro de gametocitos de $P$. falciparum. Por lo tanto, el Grupo Malaria de la Universidad de Antioquia, interesado en la obtención de este estadio del parásito y de su continua producción para la medición de la respuesta del gametocito a nuevas 
opciones terapéuticas antipalúdicas, como son los compuestos aislados de plantas, estableció un cultivo in vitro de gametocitos en el cual se obtuvieron estadios del I al V, según el protocolo de Bhattacharyya Kanti y Kumar Nirbhay(20).

En este reporte se describe la técnica de cultivo in vitro de gametocitos según el protocolo de Bhattacharyya Kanti y Kumar Nirbhay (20), y se muestran imágenes propias de los diferentes estadios, cuya morfología fue analizada por microscopía de luz y estuvo acorde con las características morfológicas de los cinco estadios del gametocito descritas en publicaciones de Cheryl Lobo y Nirbhay Kumar, 2000 (11), y Arthur Talman y colaboradores (8).

\section{Materiales y métodos}

\section{Parásitos}

Se utilizó la cepa NF54 de $P$. falciparum (cepa sensible a la cloroquina) para la producción de gametocitos.

\section{Medio de cultivo}

El medio de cultivo (1 L) se preparó según protocolo de Trager y Jensen (13), de la siguiente manera: se pesaron 10,4 g de RPMI (SIGMA), 5,94 g de hepes ácido, 2,0 $\mathrm{g}$ de dextrosa, 0,5 $\mathrm{g}$ de $\mathrm{L}$ glutamina, 0,016 $\mathrm{g}$ de sulfato de gentamicina $\mathrm{y}$ 0,026 g de hipoxantina; se adicionaron $960 \mathrm{ml}$ de agua desionizada estéril y se mezcló con agitador magnético hasta que todos los reactivos estuvieron completamente disueltos. Se filtró con membrana Millipore ${ }^{\circledR}$ de $0,22 \mu \mathrm{m}$ y se conservó a $4^{\circ} \mathrm{C}$ hasta su uso; este medio se denominó medio incompleto.

Para preparar $50 \mathrm{ml}$ de medio completo, el cual se usó para cambio de medio del cultivo de gametocitos, se tomaron $43,3 \mathrm{ml}$ de medio incompleto y se le adicionaron $5,0 \mathrm{ml}$ de suero humano $\mathrm{A}-\mathrm{Rh}^{+}$al $10 \%, 43,0 \mu \mathrm{l}$ de glutatión reducido $1 \mathrm{mg} / \mathrm{ml}(0,00326 \mathrm{M})$ y $1,8 \mathrm{ml}$ de $\mathrm{NaHCO}_{3}$ al $5 \%$ $(0,59 \mathrm{M})$. Después de la preparación de cada uno de los medios, se tomó una muestra para la prueba de esterilidad en infusión cerebro corazón (BHI), la cual se incubó a $37^{\circ} \mathrm{C}$ y se leyó a las 24, 48, y 72 horas; para la utilización de los medios, la prueba de esterilidad debía ser negativa a las 72 horas.
El suero humano se preparó a partir de una mezcla de plasma $\mathrm{A}-\mathrm{Rh}^{+}$(con pruebas biológicas de tamización negativas), en botellas de policarbonato de $1 \mathrm{~L}$ que contenían perlas de vidrio que ocupaban, aproximadamente, un cuarto de las botellas; éstas se esterilizaron en formaldehído y posteriormente se les adicionó $1,7 \mathrm{ml}$ de $\mathrm{CaCl}_{2}$ 1,5 M estéril por cada $250 \mathrm{ml}$ de plasma; se incubaron durante 6 horas a $37{ }^{\circ} \mathrm{C}$ y luego toda la noche a $4{ }^{\circ} \mathrm{C}$. Después del tiempo de incubación, se centrifugaron a $4.500 \mathrm{rpm}$ por 40 minutos a $4{ }^{\circ} \mathrm{C}$, se tomó el suero de las botellas cuidadosamente y se envasó en tubos Falcon®estériles de $15 \mathrm{ml}$. A continuación se inactivó el suero a $56^{\circ} \mathrm{C}$ durante 30 minutos y se almacenó a $-20^{\circ} \mathrm{C}$. El suero se descongeló a $37^{\circ} \mathrm{C}$ por 20 minutos antes de su uso.

\section{Lavado de glóbulos rojos}

Según el protocolo para el manejo de la cepa de $P$. falciparum in vitro del Instituto Nacional de Salud (21), los glóbulos rojos A-Rh+ de donantes locales de sangre fueron recolectados en tubos secos al vacío de $10 \mathrm{ml}$. Por cada $10 \mathrm{ml}$ de sangre se adicionó $1,4 \mathrm{ml}$ de solución anticoagulante CPD (14\%); para preparar $50 \mathrm{ml}$ de solución anticoagulante CPD (14\%) se pesaron 0,164 g de ácido cítrico, $1,317 \mathrm{~g}$ de citrato de sodio $2 \mathrm{H}_{2} \mathrm{O}$, $0,111 \mathrm{~g}$ de fosfato de sodio $1 \mathrm{H}_{2} \mathrm{O}, 1,278 \mathrm{~g}$ de dextrosa y mezclar con $50 \mathrm{ml}$ de agua desionizada estéril. Se mezcló suavemente y se almacenó a $4{ }^{\circ} \mathrm{C}$ para su preservación durante 30 a 35 días, aproximadamente.

Para el lavado de los glóbulos rojos, se tomó la sangre total que estaba a $4{ }^{\circ} \mathrm{C}$, se pasó a un tubo Falcon® de $15 \mathrm{ml}$, se centrifugó a 1.500 rpm durante 10 minutos y se descartaron el plasma y la capa de leucocitos. Posteriormente, se adicionó medio de lavado de glóbulos rojos (para preparar $100 \mathrm{ml}$ de medio de lavado: se toman $96,4 \mathrm{ml}$ de medio incompleto y se mezclan con $3,6 \mathrm{ml}$ de $\mathrm{NaHCO}_{3}$ previamente preparado a una concentración de $5 \%(0,59 \mathrm{M})$ en una proporción 2:1 (medio incompleto: glóbulos rojos); se mezcló suavemente por inversión, se centrifugó a 1.500 rpm durante 10 minutos y con una pipeta Pasteur se descartaron el sobrenadante y, aproximadamente, $100 \mu \mathrm{l}$ de la superficie del sedimento de glóbulos rojos. El lavado se repitió tres veces. 
Los glóbulos rojos lavados se conservaron a $4{ }^{\circ} \mathrm{C}$ hasta su uso.

\section{Cultivo de gametocitos}

Procedimento de cultivo de gametocitos: la cepa NF54 de $P$. falciparum se cultivó in vitro para producción de gametocitos, según protocolo de cultivo de Bhattacharyya Kanti y Kumar Nirbhay (20). El procedimiento que se aplicó fue el siguiente: el cultivo in vitro de Plasmodium con un volumen final de $10 \mathrm{ml}$ (hematocrito del $6 \%$ de sangre A$\mathrm{Rh}+\mathrm{y}$ una parasitemia de $0,3 \%$ de NF54 de $P$. falciparum), se envasó en botella de cultivo; posteriormente, se adicionó por 20 segundos mezcla de gases $\left(90 \% \mathrm{~N}_{2}, 5 \% \mathrm{O}_{2}, 5 \% \mathrm{CO}_{2}\right)$ y se colocó a incubar la botella en posición horizontal a $37^{\circ} \mathrm{C}$.

Al cultivo se le adicionaron los glóbulos rojos sólo el primer día y se le cambió el medio diariamente; se eliminó el medio viejo que tenia la botella, se dejó un pequeño volumen de, más o menos, $1 \mathrm{ml}$ de medio por cada $5 \mathrm{ml}$ de cultivo para evitar tomar glóbulos rojos; se tomaron, aproximadamente, 4 $\mu \mathrm{l}$ de glóbulos rojos del fondo de la botella de cultivo con los que se hizo un extendido en una placa portaobjetos, se coloreó con Giemsa y se determinó el crecimiento de la parasitemia asexual y sexual. Después de desechar el medio viejo, se le agregó medio completo nuevo (8 ml) y se adicionó por 20 segundos la mezcla de gases $\left(90 \% \mathrm{~N}_{2}, 5 \% \mathrm{O}_{2} ; 5 \% \mathrm{CO}_{2}\right)$. Durante el cambio de medio se aseguró que el cultivo no estuviera por debajo de $37^{\circ} \mathrm{C}$; para esto se cambió el medio rápidamente, colocando la botella de cultivo sobre una placa de Petri que se puso en una plancha a $37^{\circ} \mathrm{C}$ por 5 minutos, previo al cambio de medio. El cultivo fue manipulado siempre bajo condiciones de esterilidad.

Cuando la parasitemia asexual del cultivo estuvo entre 3\% y $5 \%$, se comenzó a agregar el doble de volumen de medio completo $(16 \mathrm{ml}$ ) diariamente.

Según el protocolo de Bhattacharyya Kanti y Nirbhay Kumar (20), alrededor de los días 14 a 18 del cultivo se obtendrían gametocitos maduros (estadio V). Nosotros mantuvimos el cultivo hasta el día 14 porque en un ensayo previo de 17 días se vio que, después del día 15 , se presentaron una disminución de glóbulos rojos y alteraciones morfológicas en los gametocitos que no permitían realizar una buena diferenciación de sus estadios.

\section{Determinación de la parasitemia}

Se hizo seguimiento diario de las parasitemias en extendidos de sangre periférica coloreados con Giemsa, según el protocolo del Instituto Nacional de Salud (21). Se llevó un registro diario de los conteos, expresados en porcentaje, de glóbulos rojos parasitados por formas asexuales y formas sexuales en $10^{3}$ glóbulos rojos. Estos conteos se llevaron a cabo en 11 campos de 300 glóbulos rojos cada uno, aproximadamente, y se calculó la parasitemia tomando el número de glóbulos rojos parasitados multiplicado por tres y dividido por 100.

\section{Resultados}

Al realizar el análisis morfológico y la clasificación de estadios de $P$. falciparum en el cultivo, se observaron estadios asexuales y gametocitos morfológicamente diferenciables desde el primer día de seguimiento, los cuales se clasificaron con base en las características descritas $(8,11)$. Esta coexistencia de estadios sexuales y asexuales del parásito posiblemente se debió a que el cultivo se encontraba sin sincronizar y, de esta manera, pueden aparecer parásitos asexuales que comienzan a diferenciarse en gametocitos y parásitos con predisposición genética para formación de gametocitos. Igualmente, a partir del día 12 del cultivo de gametocitos se observó morfológicamente mayor cantidad de gametocitos compatibles con las características morfológicas de los estadios IV y V descritas por Cheryl Lobo y Nirbhay Kumar en 2000 (11), y Arthur M. Talman y colaboradores en 2004 (8). Aun en el día 14 en el que se finalizó el mantenimiento del cultivo, se observaron gametocitos $\mathrm{V}$ maduros. Además, el porcentaje de glóbulos rojos parasitados con gametocitos fue mayor de $1 \%$ a partir del día 4 de cultivo y se mantuvo por encima de este porcentaje hasta el día 14 de su mantenimiento, lo que indica que el presente cultivo permite obtener diariamente producción de gametocitos durante todo el tiempo de sostenimiento del cultivo (cuadro 1).

Cuando se realizó diariamente la relación entre formas asexuales y sexuales de la cepa NF54 de 
$P$. falciparum en cultivo, se observó que hubo un mayor porcentaje de glóbulos rojos parasitados con estadios asexuales que de glóbulos rojos parasitados con formas sexuales; la diferencia representó un $2,7 \%$ más.

Al efectuar el análisis morfológico de los gametocitos según Arthur $M$. Talman y colaboradores (8), y Cheryl Lobo y Nirbhay Kumar (11), se observaron en el cultivo de la cepa NF54 de $P$. falciparum gametocitos desde el estadio I hasta el estadio V. Durante los primeros 11 días del cultivo se observaron en su mayoría gametocitos compatibles con los estadios I, II y III (figuras 1, 2 y 3); los días siguientes se comenzaron a observar en su mayoría gametocitos compatibles con los estadios 4 y 5 (figuras 4,5 y 6) y el día 14, último día del mantenimiento del cultivo, en su mayoría se observaron gametocitos compatibles con el estadio $\mathrm{V}$ maduro, los cuales presentaron características morfológicas que permitieron diferenciarlos en microgametocito (macho) (figura 5) y macrogametocito (hembra) (figura 6).

\section{Discusión}

El gametocito ha sido una forma parasitaria poco estudiada, a pesar de cumplir un papel crítico en la continuación del ciclo de vida del parásito que ocasiona la malaria por medio de su transmisión del hombre al mosquito vector Anopheles. Se ha comprobado que la presión de los medicamentos antipalúdicos que no ejercen una acción gametocida puede también aumentar la producción de gametocitos y, de esta manera, intensificar la transmisión (22). Igualmente, estudios in vivo demuestran que parásitos resistentes producen gametocitos más infectantes para el mosquito (23). Es por esto que los gametocitos constituyen un potencial blanco para combatir la malaria por medio de nuevas alternativas antipalúdicas y, de esta manera, lograr reducir la transmisión. Para esto es necesaria su producción en cantidad suficiente y que permanezcan infectantes para el mosquito para permitir el desarrollo de estudios futuros. En este estudio el protocolo de cultivo in vitro descrito por Bhattacharyya Kanti y Nirbhay Kumar (20), se llevó a cabo en su totalidad con la cepa NF54 de $P$. falciparum y con él se pudo reproducir el desarrollo de gametocitos de $P$. falciparum y obtenerlos en sus diversos estadios.

Al analizar el cultivo se observó que, durante su mantenimiento, los gametocitos se encontraron siempre acompañados del estadio asexual. Se han reportado diversas técnicas que utilizan sustancias químicas que eliminan los estadios asexuales, como la mitomicina C (24), la pirimetamina (25) y el sorbitol (26), aunque el uso de estas sustancias generó ciertos inconvenientes

Cuadro 1. Porcentajes y proporción de estadio asexual y sexual de cultivo de NF54 de P. falciparum durante 14 días de seguimiento.

\begin{tabular}{|c|c|c|c|c|c|c|c|}
\hline Día & Cepa & Anillos & Trofozoítos & $\begin{array}{c}\text { Esquizontes } \\
(\%)\end{array}$ & Asexuales & Sexuales & $\begin{array}{c}\text { Proporción asexuales: } \\
\text { gametocitos }\end{array}$ \\
\hline 0 & NF54 & 0 & 0 & 0 & 0 & 0 & $0: 0$ \\
\hline 1 & NF54 & 0,36 & 0,18 & 0,21 & 0,76 & 0,15 & $5: 1$ \\
\hline 2 & NF54 & 1,36 & 0,12 & 0,21 & 1,7 & 0,18 & $9,3: 1$ \\
\hline 3 & NF54 & 1,55 & 0,24 & 0,76 & 2,55 & 0,76 & $3,4: 1$ \\
\hline 4 & NF54 & 4,09 & 1,06 & 1,64 & 6,79 & 1,30 & $5,2: 1$ \\
\hline 5 & NF54 & 1,7 & 0,58 & 0,94 & 3,21 & 2,45 & 1,3:1 \\
\hline 6 & NF54 & 3,33 & 0,33 & 1,76 & 5,42 & 1,15 & $4,7: 1$ \\
\hline 7 & NF54 & 4,24 & 0,55 & 0,85 & 5,64 & 2,3 & $2,4: 1$ \\
\hline 8 & NF54 & 3,03 & 0,52 & 1,73 & 5,27 & 1,61 & $3,3: 1$ \\
\hline 9 & NF54 & 1,06 & 0,12 & 1,03 & 2,21 & 1,30 & $1,7: 1$ \\
\hline 10 & NF54 & 4,3 & 0,03 & 2,03 & 6,36 & 2,42 & $2,6: 1$ \\
\hline 11 & NF54 & 3,42 & 0,36 & 1,88 & 5,67 & 2,21 & $2,6: 1$ \\
\hline 12 & NF54 & 3,09 & 0,30 & 1,21 & 4,61 & 1,76 & $2,6: 1$ \\
\hline 13 & NF54 & 3,12 & 0,06 & 1,76 & 4,94 & 1,67 & $3: 1$ \\
\hline
\end{tabular}




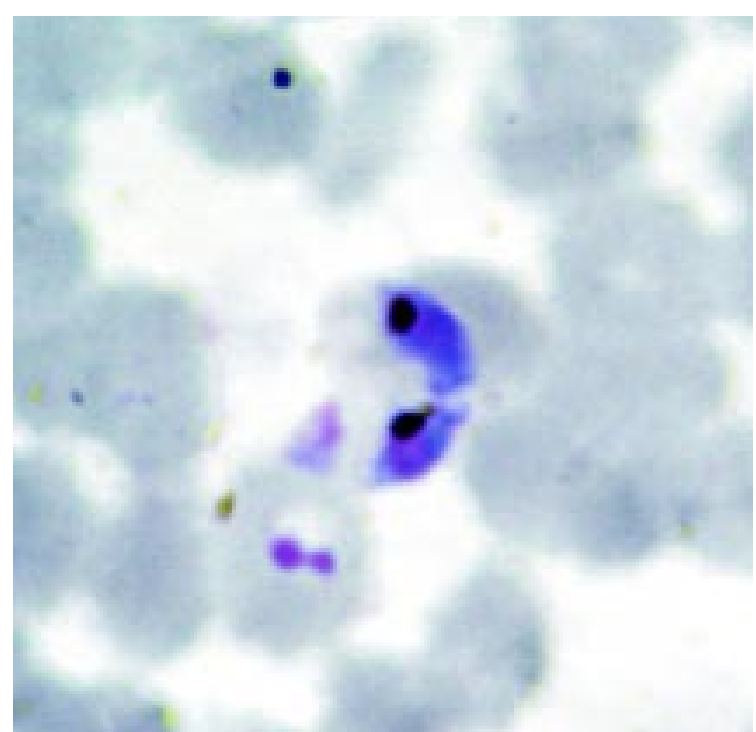

Figura 1. Gametocito estadio I de cultivo in vitro de $P$. falciparum NF54, Giemsa, 100X. Gametocito estadio I: subdividido en estadio IA indistinguible de la forma redondeada del trofozoito joven, y estadio IB cuya forma es redondeada alargada con distribución granular de pigmento. Núcleo dimórfico, plasmalema no alterado y debajo de este se observa una pequeña vesícula membranosa aplanada sobre un arsenal de microtubulos orientados longitudinalmente.

como la obtención de un número reducido de gametocitos, no eliminar estadios asexuales resistentes a la pirimetamina y la ausencia de producción de gametocitos funcionales.

Otra técnica desarrollada es el uso de gradientes de Percoll (27), la cual ha sido probada por nosotros, observándose que después de someter el cultivo de gametocitos a diferentes gradientes de Percoll, se concentran los glóbulos rojos parasitados con estadios sexuales y se observa un aumento del porcentaje de estos al compararlo con el porcentaje previo a la purificación. Además de permitir la obtención de un cultivo puro de gametocitos, esta técnica facilita la separación de todos los estadios de gametocitos. Es así como se podrían emplear métodos como éste para obtener únicamente gametocitos en cada uno de sus estadios de desarrollo y estudiar de una manera más amplia su biología.

Una característica importante en el cultivo que se desarrolló fue que los estadios maduros que

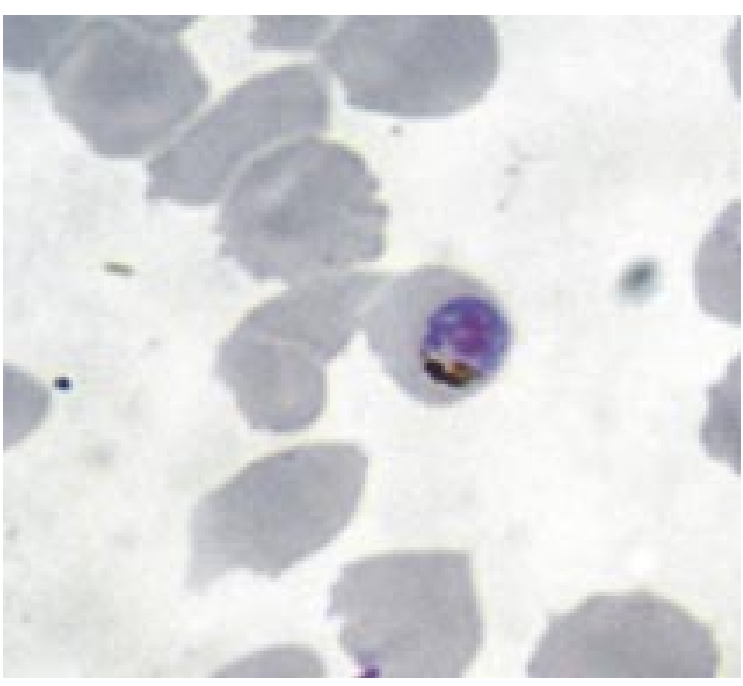

Figura 2. Gametocito estadio II de cultivo in vitro de $P$. falciparum NF54, Giemsa, 100X. Gametocito estadio II: clasificado en IIA el cual se alarga dentro del eritrocito y IIB el cual adquiere una forma de "D" debido a que se extiende la vesícula membranosa y los microtubulos, el núcleo se alarga a lo largo del eje de la célula.

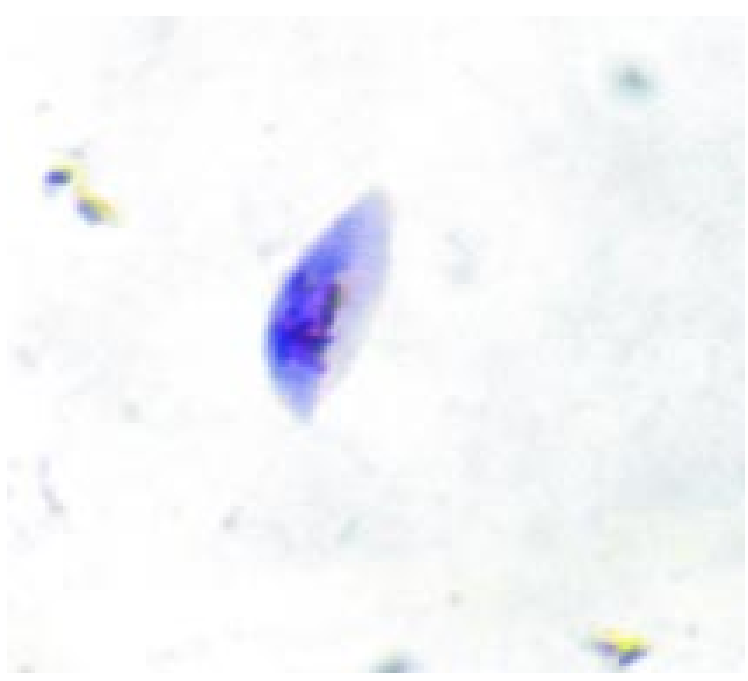

Figura 3. Gametocito estadio III de cultivo in vitro de $P$. falciparum NF54, Giemsa, 100X. Gametocito estadio III: estadio en el que se comienza a diferenciar microscópicamente el gametocito hembra y macho, se observa notablemente la forma de "D", el citoplasma del gametocito macho toma color rosado y el citoplasma del gametocito hembra toma color azul; el núcleo del gametocito macho es notablemente más largo (también llega a ser lobulado) que el del gametocito hembra. 


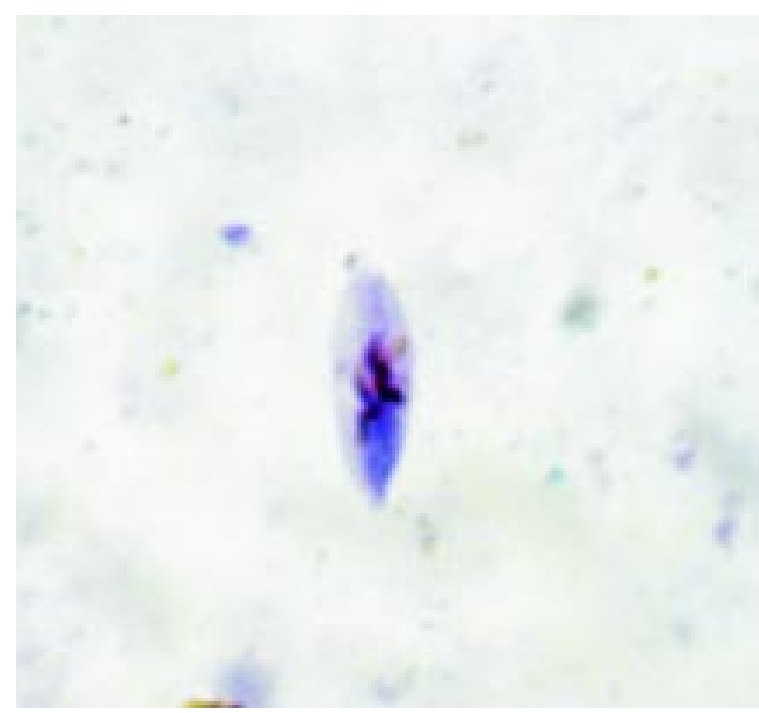

Figura 4. Gametocito estadio IV de cultivo in vitro de $P$. falciparum NF54, Giemsa, 100X. Gametocito IV: es simétrico, morfológicamente alargado y delgado, distorsiona el eritrocito, el pigmento del gametocito macho tiende a ser disperso y el gametocito hembra posee un pigmento más denso. Ultraestructuralmente, el complejo de membrana y los microtúbulos envuelven completamente el gametocito, el dimorfismo sexual se acentúa en este estadio.

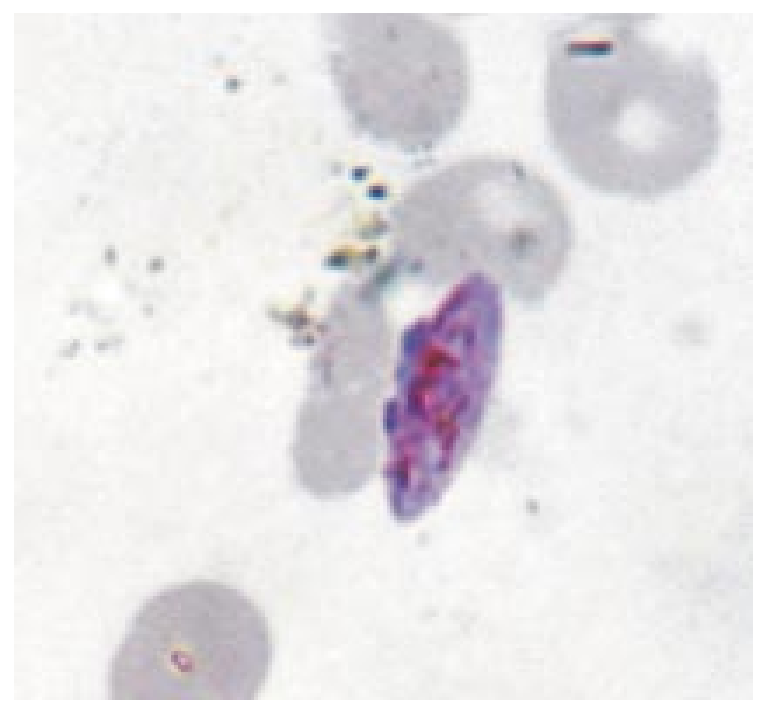

Figura 5. Gametocito estadio $\mathrm{V}$ de cultivo in vitro de $P$. falciparum NF54. Microgametocito (gametocito macho), Giemsa, 100X. Gametocito V macho: Forma de "salchicha", con los extremos redondeados, posee un pigmento disperso, rosado y un núcleo alargado.

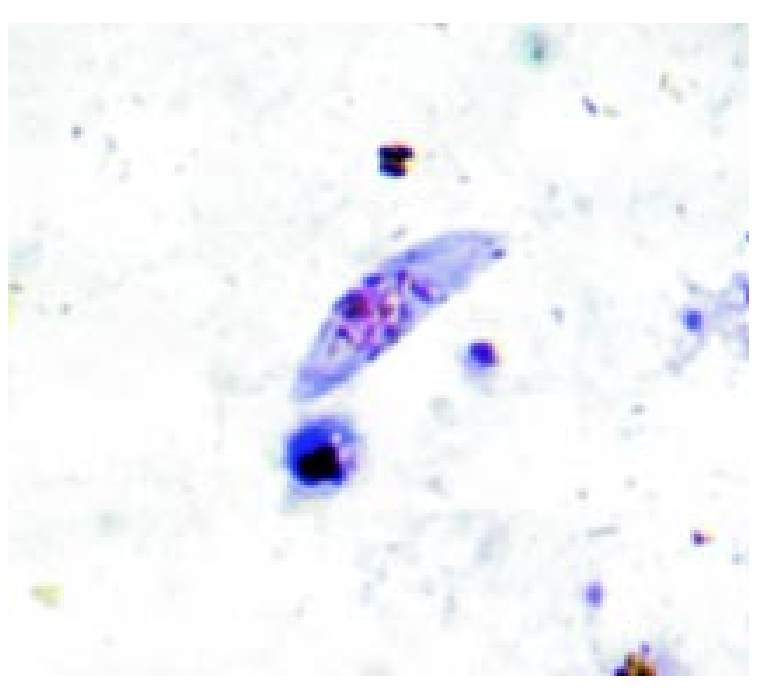

Figura 6. Gametocito estadio $V$ de cultivo in vitro de $P$. falciparum NF54; macrogametocito (gametocito hembra). (Giemsa, 100x). Gametocito VI hembra; Forma de "salchicha", con los extremos redondeados, el posee un pigmento denso, violáceo y un núcleo pequeño.

se comenzaron a obtener a partir del día 11 del cultivo se lograron diferenciar morfológicamente en macrogametocitos (gametocitos hembras) y microgametocitos (gametocitos machos) y, a partir del día 14, se observaron mucho mejor sus características morfológicas, situación que podría permitir el inicio de estudios de capacidad infecciosa con estos estadios de gametocitos maduros de la cepa NF54 de $P$. falciparum.

Existen algunas diferencias con otros autores en relación con la técnica de cultivo de gametocitos, pero no son significativas. Por ejemplo, J. B. Jensen (28), produjo la maduración morfológica de gametocitos después del día 8 de cultivo y no logró la exflagelación in vitro, por lo cual se menciona que estos gametocitos no son funcionales para estudios futuros. R. S. Phillips y colaboradores (29), utilizaron para el cultivo de gametocitos glóbulos rojos fetales, los cuales suministraron un ambiente favorable para el crecimiento de los gametocitos. En otros artículos se encontró el uso de químicos, como la hipoxantina, que nosotros también adicionamos al cultivo para permitir la maduración de los gametocitos (15). 
En Colombia no se ha reportado hasta ahora ningún estudio sobre cultivo in vitro de gametocitos de $P$. falciparum. Éste se llevó a cabo por el Grupo de Malaria de la Universidad de Antioquia, dada la necesidad de realizar estudios más amplios con los gametocitos, tales como estudios que permitan conocer su proceso de desarrollo (gametocitogénesis), sus mecanismos de citoadherencia, sus procesos metabólicos, la expresión de genes, la inmunidad contra sus diversos estadios, su capacidad infecciosa, sus estrategias de transmisión y evolución, y además, conocer su respuesta a medicamentos antipalúdicos. Sin embargo, es necesario saber si todas las cepas de $P$. falciparum tienen la misma posibilidad de producir gametocitos que la cepa NF54 de $P$. falciparum empleada en este cultivo, la cual fue exitosa en la producción de gametocitos en estadio I, II, III, IV y V.

Esperamos continuar con el estudio de los gametocitos encontrando nuevos blancos para intervenir en el control del paludismo, además de estudiar el patrón de la resistencia a los antipalúdicos, enfocados en nuevos fármacos, que no sólo eliminen los estadios asexuales del parásito sino también a los estadios sexuales, y finalmente, contribuir en el bloqueo de la transmisión del paludismo.

\section{Agradecimientos}

A la Universidad de Antioquia y al Grupo Malaria, especialmente a Cecilia Giraldo Castro, bacterióloga de asistencia.

\section{Conflictos de intereses}

El manuscrito fue preparado y revisado con la participación de todos los autores, quienes declaramos que no existe ningún conflicto de intereses que ponga en riesgo la validez de nuestros resultados.

\section{Financiación}

Este trabajo fue financiado por la Universidad de Antioquia y el Grupo Malaria.

\section{Referencias}

1. Schneider P, Schoone G, Schallig H, Verhage D, Telgt D, Eling W, et al. Quantification of Plasmodium falciparum gametocytes in differential stages of devel- opment by quantitative nucleic acid sequence-based amplification. Mol Biochem Parasitol. 2004;137:35-41.

2. Shute PG, Maryon M. A study of gametocytes in a West African strain of Plasmodium falciparum. Trans $\mathrm{R}$ Soc Trop Med Hyg. 1951;44:421-38.

3. Eichner M, Diebner HH, Molineaux L, Collins WE, Jeffery GM, Dietz K. Genesis, sequestration and survival of Plasmodium falciparum gametocytes: parameter estimates from fitting a model to malaria therapy data. Trans R Soc Trop Med Hyg. 2001;95:497-501.

4. Sinden RE. Sexual development of malaria parasite. Adv Parasitol. 1983;22:153-216.

5. Kitchen SF, Putnam P. Observations on the mechanism of the parasite cycle in falciparum malaria. Am J Trop Med. 1942; 22:361-86.

6. Kitchen SF. Falciparum malaria. En: Boyd MF, editor Malariology. Philadelphia: WB Saunders; 1949. p. 9951016.

7. Carter R, Graves PM. Gametocytes. En: Wernsdorfer WH, McGregor SI, editors. Malaria: principles and practice of malariology. First edition. Edinburgh, Scotland: Churchill Livingstone; 1988. p. 1-59.

8. Talman AM, Domarle O, Mckenzie FE, Ariey F, Robert V. Gametocytogenesis: the puberty of Plasmodium falciparum. Malar J. 2004,3:24.

9. Hawking F, Wilson ME, Gammage K. Evidence for cyclic short-lived maturity in the gametocytes of Plasmodium falciparum. Trans R Soc Trop Med Hyg. 1971;65:549-59.

10. Field JW, Shute PG. The microscopic diagnosis of human malaria. A morphological study of erythrocytic parasites. Kuala Lumpur, Malaysia: Institute for Medical Research, Government Press; 1956. p. 142.

11. Lobo CA, Kumar N. Sexual differentiation and development in the malaria parasite. Parasitol Today. 1998;14:146-50.

12. Row R. On some observation on the malarial parasites grow aerobically in simple cultures with special reference to the evolution and degeneration of the crescents. Indian J Med Res. 1929;16:120-7.

13. Trager W, Jensen JB. Human malaria parasite in continuous culture. Science. 1976;193:673-5.

14. Smalley ME. Plasmodium falciparum gametocytogenesis in vitro. Nature. 1976;264:271-2.

15. Ifediba T, Vanderberg JP. Complete in vitro maturation of Plasmodium falciparum gametocytes. Nature. 1981;294:364-6.

16. Ponnudurai T, Meuwissen JH, Leeuwenberg AD, Verhave JP, Lensen AH. The production of mature gametocytes of Plasmodium falciparum in continuous cultures of different isolates infective to mosquitoes. Trans R Soc Trop Med Hyg. 1982;76:242-50. 
17. Freese JA, Sharp BL, Ridl FC, Markus MB. In vitro cultivation of southern African strains of Plasmodium falciparum and gametocytogenesis. S Afr Med J .1988;73:720-2.

18. Ponnudurai T, Lensen AH, Meuwissen JH. An automated large - scale culture system of Plasmodium falciparum using tangential flow filtration for medium change. Parasitology. 1983;87:439-45.

19. Ponnudurai T, Lensen AH, Meis JF, Meuwissen JH. Synchronization of Plasmodium falciparum gametocytes using an automated suspension culture system. Parasitology. 1986;93:263-74.

20. Kanti BM, Kumar N. Plasmodium falciparum gametocyte culture, purification, and gametogenesis. In: Ljungström I, Perlmann $\mathrm{H}$, Schlichtherle $\mathrm{M}$, Scherf A, Wahlgren $M$, editors. Methods in malaria research. Fourth edition. Manassas, Virginia; MR4/ATCC; 2004. p. 93-4.

21. Instituto Nacional de Salud. Protocolos para el manejo de la cepa de $P$. falciparum in vitro. Bogotá. Instituto Nacional de Salud; 1989. p. 28.

22. Ali E, Mackinnon MJ, Abdel-Muhsin AM, Ahmed S, Walliker D, Babiker HA. Increased density but not prevalence of gametocytes following drug treatment of Plasmodium falciparum. Trans R Soc Trop Med Hyg. 2006;100:176-83.

23. Sutherland CJ, Alloueche A, Curtis J, Drakeley CJ, Ord R, Duraisingh M, et al. Gambian children suc- cessfully treated with chloroquine can harbor and transmit Plasmodium falciparum gametocytes carrying resistance genes. Am J Trop Med Hyg. 2000;67:578-85.

24. Sinden RE, Ponnudurai T, Smits MA, Simm AM, Meuwissen JH. Gametocytogenesis of Plasmodium falciparum in vitro: a simple technique for the routine culture of pure capacitated gametocytes en masse. Parasitology. 1984;88:239-47.

25. Chutmongkonkul M, Maier WA, Seitz HM. A new model for testing gametocytocidal effects of some antimalarial drugs on Plasmodium falciparum in vitro. Ann Trop Med Parasitol. 1992;86:207-15.

26. Saul A, Graves P, Edser L. Refractoriness of erythrocytes infected with Plasmodium falciparum gametocytes to lysis by sorbitol. Int J Parasitol. 1990;20:1095-7.

27. Kariuki MM, Kiaira JK, Mulaa FK, Mwangi JK, Wasunna MK, Martin SK. Plasmodium falciparum: Purification of the various gametocyte developmental stages from in vitro-cultivated parasites. Am J Trop Med Hyg. 1998;59:505-8.

28. Jensen JB. Observations on gametogenesis in Plasmodium falciparum from continuous culture. J Protozool. 1979;26:129-32.

29. Phillips RS, Wilson RJ, Pasvol G. Differentiation of gametocytes in microcultures of human blood infected with Plasmodium falciparum. J Protozool. 1978;25:394-8. 